\title{
Treatment of midshaft clavicle fracture with anatomical contoured clavicular locking plate
}

\author{
Pratyenta Raj Onta', Krishna Sapkota ${ }^{2}$, Krishna Wahegaonkar ${ }^{3}$, Niraj Ranjeet ${ }^{2}$, \\ Pabin Thapa ${ }^{1}$, Upendra Jung Thapa ${ }^{1}$ \\ ${ }^{1}$ Lecturer, Department of Orthopedics, Manipal Teaching Hospital, Phulbari, Pokhara, Nepal, ${ }^{2}$ Assistant Professor, \\ Department of Orthopedics, Manipal Teaching Hospital, Phulbari, Pokhara, Nepal. ${ }^{3}$ Associate Professor, Department of \\ Orthopedics, Manipal Teaching Hospital, Phulbari, Pokhara, Nepal.
}

Background: Fracture clavicle is a common fracture around the shoulder joint accounting about $2.6 \%$ of all fracture and $44 \%$ in shoulder region. Mid shaft clavicle fracture accounts about $81 \%$ of total clavicle fracture. Open reduction and plate fixation is a good treatment method for displaced mid shaft clavicle fracture with benefit of early pain free movement of shoulder joint and early return to work. The anatomical contoured clavicular plate maintains mechanical strength and has less soft tissue complications. Aims and Objective: The aim of the study was to evaluate the clinical and radiological outcome, time for fracture union and complications in midshaft clavicle fracture managed with anatomical contoured clavicular locking plate. Material and Methods: This study was done in Manipal Teaching Hospital, Pokhara, Nepal.There were a total of 30 patients ( 19 male and 11 female) who had displaced mid shaft fracture. All patients underwent plate osteosynthesis with anatomical contoured locking plate. The patients were followed up at 3 weeks, 6 weeks, 3 month and 6 months' time. Results: There were 30 patients among whom; one patient had bilateral clavicle fracture. The mean age of the patient was 37.19 (11.96) years. The mean time for clinical and radiological union was 8.77 (1.17) weeks and 17.03 (3.06) weeks. All patients in our study had union of fracture with only one patient having superficial surgical site infection. Conclusion: Open reduction and plate fixation is a good option for displaced mid shaft clavicle fracture which help the patient for early pain-free movement of shoulder. Use of anatomical contoured clavicle plate provides fixation of clavicle to its normal contour and provides better fixation and stability.

Key words: Anatomical plate; Midshaft clavicle fracture; Open reduction and Internal fixation

\section{INTRODUCTION}

In the past days, the management of midshaft clavicle fracture was entirely conservative but due to various complications of conservative management like nonunion, malunion, cosmetic values and the effect in shoulder biomechanics the trend has now shifted to operative management for displaced midshaft clavicle fracture. ${ }^{1-6}$ The reasons for shifting of management protocol from conservative to operative are maintenance of shoulder biomechanics by preventing shortening, early mobilization of shoulder, early pain relief and early return to work. ${ }^{6-8}$
Beside this, in recent years there were lots of studies that showed good results with operative treatment. ${ }^{6,7,9-11}$

Even though there are many advantages of operative management of midshaft clavicle fracture, the procedure is not free of disadvantages like effect of anesthesia, scar mark, hardware prominence, nonunion, neurovascular injuries, infection and so on. ${ }^{12-14}$ There are various methods of operative fixation of midshaft clavicle fracture like intramedullary flexible nailing, screw fixation, recon plating and anatomical plating. Open reduction and plating is considered gold standard method 
for midshaft clavicle fracture. ${ }^{15}$ The use of anatomical contoured clavicular locking plate is better option because the surgeon does not need to contour the plate which retains the mechanical strength of the plate and has less soft tissue related problems. ${ }^{16}$ The precontoured plate has an added benefit of less hardware prominence which decreases the need of removal of implant after healing of fracture as compared to traditional plate. ${ }^{17}$

\section{MATERIALS AND METHODS}

This was a prospective study. All patients with midshaft clavicle fracture who attended the OPD of orthopedics and emergency department of Manipal Teaching Hospital from January 2017 to January 2018 were evaluated as per inclusion and exclusion criteria of the study.

The inclusion criteria for the study were:

1. Midshaft clavicular fracture with displacement and shortening of more than $2 \mathrm{~cm}$.

2. Segmental fracture.

3. Age between 16 to 60 years

4. Type I and II open fracture

5. Bilateral clavicular fracture.

The exclusion criteria were:

1. Age less than 16 years or greater than 60 years

2. Fracture in the proximal or distal third of the clavicle

3. Pathological fracture

4. Fracture more than 3 weeks after the injury

5. Associated neurovascular injury

6. Associated head injury

7. Medical contraindicated to surgery and/or anesthesia.

There were total 30 patients ( 19 male and 11 female) with one of the male patient had bilateral clavicle fracture that met the inclusion criteria of this study. All the patients were subjected to plate osteosynthesis after obtaining informed and written consent. The pros and cons of the operative fixation were explained individually.Ethical approval was obtained from Institutional ethical Review Committee (IRC) before the study was carried out.

\section{Operative procedure}

General anesthesia was given in all patients and placed supine in beach chair position. A bolster was placed between the scapulae to allow the shoulder to fall back which helped in reducing the fracture. The head was turned to the opposite side. The part was prepared, painted with $10 \%$ povidone-iodine solution and draped in standard fashion. Oblique incision was made centering over the fracture site of the clavicle. Subcutaneous tissue and platysma was raised as a flap. Supra clavicular nerves was identified, isolated and spared wherever possible. Fracture site was opened and curettage done. Open reduction of fracture was done and appropriate size anatomical countered clavicular locking plate was used to fix the fracture on the antero-superior surface of the bone. Inter fragmentary lag screws was used whenever needed. Wound washed with normal saline. After securing proper hemostasis, the wound was closed in layers. Arm sling or pouch was given to all patients for 2 weeks. Wound inspection and dressing was done on $3^{\text {rd }}$ post-operative dayand suture was removed after 2 weeks. Patients were usually discharged on $5^{\text {th }}$ post-operative day. Elbow, wrist and finger range of movement exercises were started as soon as the pain decreased. Patients were followed up at 2 weeks, 6 weeks, 3 months and 6 months' time. In every visit, patients were assessed clinically and radiologically for the outcome measures. Figure 1 shows the preoperative $\mathrm{X}$-ray with displaced mid shaft clavicle fracture. Figure 2 shows immediate post-operative X-ray after plating, figure 3 shows uniting fracture at 3 months follow up and Figure 4 shows united fractures at 6 months follow up.

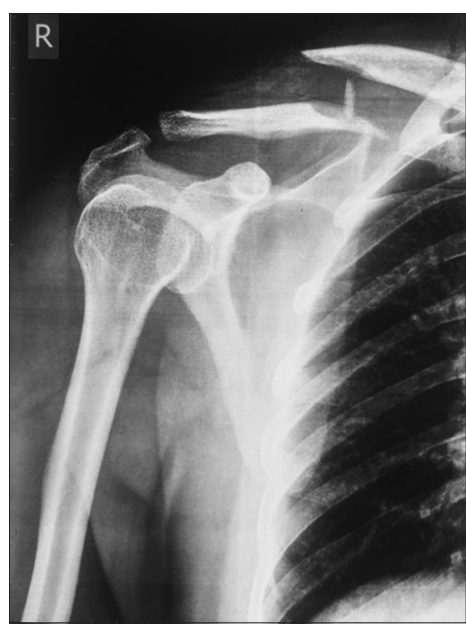

Figure 1: Pre-operative X-ray

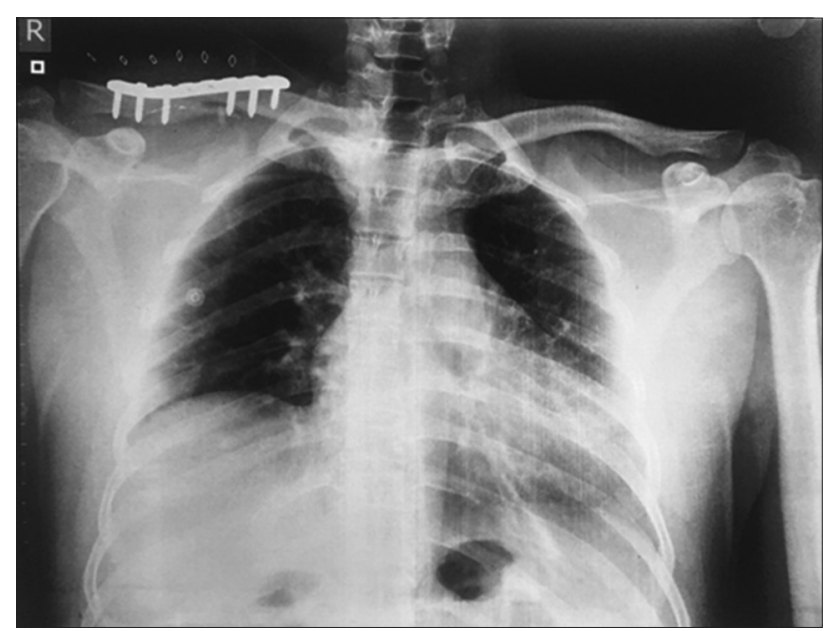

Figure 2: Post-operative X-ray 


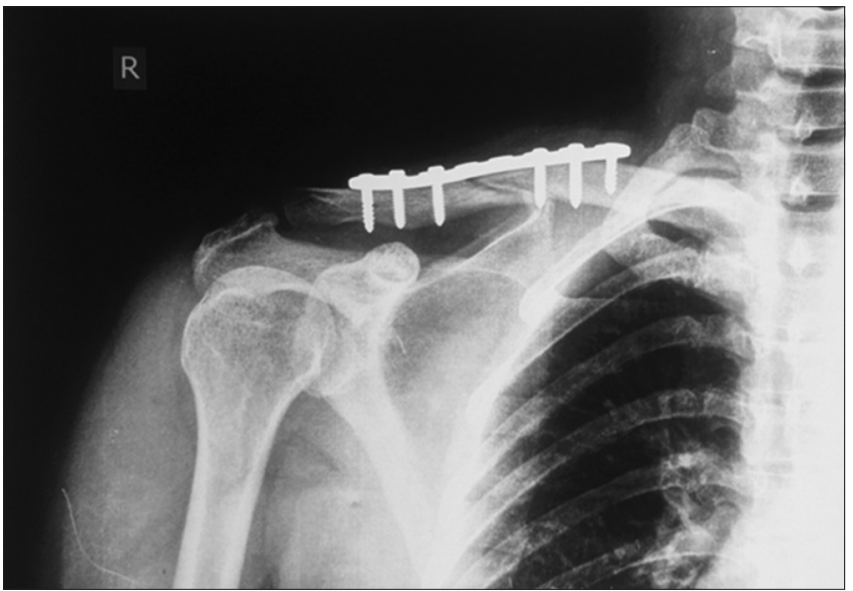

Figure 3: Follow up at 3 month

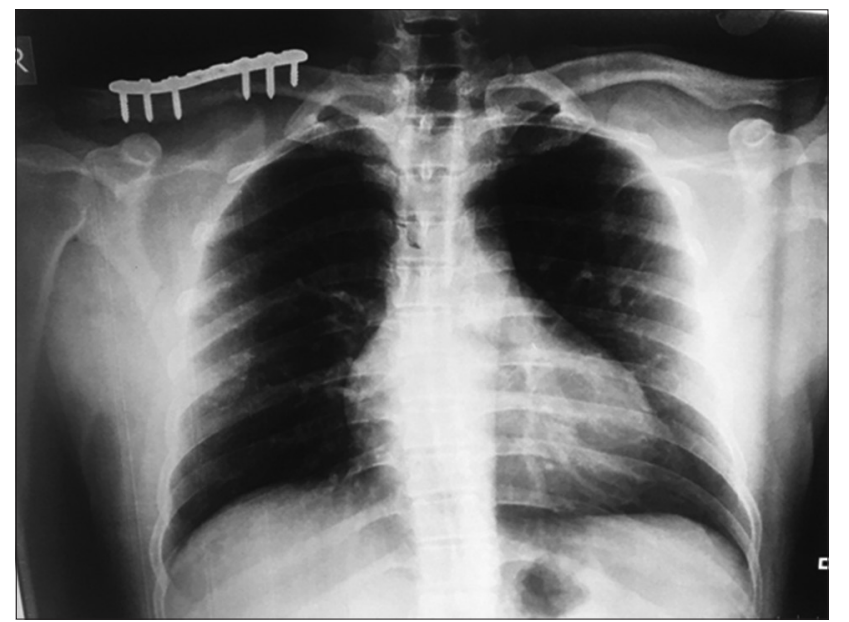

Figure 4: Follow up at 6 month with union of fracture

\section{RESULTS}

There were 30 patients with 31 cases (one case with bilateral clavicle fracture) in this study. There were 19 male and 11 female in this study. The mean age group was 37.19 (11.92) years with the range of 21 years to 59 years. There were 21 right side clavicle fracture and 10 leftsided clavicle fracture. In 12 patients the fracture was comminuted. The mode of injury was road traffic accident in $20(64.5 \%)$ patient followed by fall injury in $8(25.8 \%)$ patient and sport injury in $3(9.7 \%)$ patients. There was only $2(6.5 \%)$ cases with type I open fracture. Five patients in our case had associated injuries among whom one patient had ipsilateral distal radius fracture and one patient had contra lateral distal radius fracture. One patient had ipsilateral fracture of shaft of humerus. All three patients had fixation of fracture with operation management. One of the patients had ipsilateral ribs fracture without pneumothorax or hemothorax and did not need any active intervention. One patient had contralateral acetabulum and inferior rami fracture that was also treated conservatively.
Clinical union was considered when the patient had painless movement of shoulder. The mean time duration for clinical union in our study was 8.77 (1.17) weeks with the range of 7 to 12 weeks. The mean time for overhead activity was 4.97 (1.27) weeks with range of 4 to 8 weeks. Radiological union was seen from 12 to 22 weeks with the mean time period of 17.03 (3.06) weeks. There were no major complications in our study. Three patients had hardware prominence but did not bother the patient. Only one patient had superficial surgical site infection which was treated adequately with intravenous and oral antibiotics. None of our patient had nonunion.

\section{DISCUSSION}

Fracture clavicle is now a common injury around the shoulder joint. Clavicle fracture accounts about 2.6\% of all fracture and $44 \%$ in shoulder fracture. Among all the clavicle fracture mid shaft fracture accounts about $81 \%{ }^{18}$ The incidence of fracture clavicle is increasing day-to-day due to the motor vehicle accidents and sports activity. ${ }^{19,20}$ Since these fractures are usually seen in active people who needs to use the shoulder joint for day-to-day activity and due to need of early return to work the patients now a days choose operative management rather than conservative management. Open reduction and plate fixation gives patient early pain-free movement thus helps the patient return to their daily work soon.

In 1968 Neer's study on fracture clavicle showed that the nonunion rate in conservative management was only $1 \%{ }^{2}$ This study became the base for conservative management of fracture clavicle. Later on there were many studies which showed that the rate of nonunion was much higher in patients who underwent conservative management then what Neer's study showed. The study done by Robinson showed nonunion in $9.5 \%$ of cases similarly the study done by Hill et al and White et al showed nonunion rate of $15 \%$ and $13 \%$ respectively. ${ }^{19,21,22}$

A study done in 2007 by McKee et al compared non operative treatment with plate fixation for displaced midshaft clavicle fracture showed good result in patients who had undergone plating. In his study two (3.2\%) out of 62 patient with plate fixation had nonunion. The rate of nonunion was much higher i.e. $7(14.2 \%)$ out of 49 patient in patients with nonoperative management. The wound site infection rate was $4.8 \%$ that was treated with antibiotics. ${ }^{23}$

The mean age group in our study was 37.19 years (21-59 years) which was similar to the study done by Bostman et al 33.4 years (19-62 years), Ankur Mittal et 41.5 years (16-59 years), Prabhu Mitiraj et al 32 years 
(19-55 years) and Wali PC and Nesari SS study 37.3 years (22-65 years). ${ }^{12,24-26}$ These all studies show that the fracture clavicle usually occurs in young and active people.

All patients in our study had union of fracture. The mean time for clinical union of fracture was 8.77 weeks and the mean time for radiological union was 17.03 weeks (12-22 weeks) which was similar to the study done by Simonian TL et al was 19.28 weeks, E Mohamed et al was 14.2 weeks, Dhoju et al was 16 weeks and Olivier et al was 12 weeks. ${ }^{27-30}$

In the study done by Poigenfuerst et al 9 patients out of $122(7.3 \%)$ had superficial wound infection but no cases of osteomyelitis or infected pseudo arthritis. ${ }^{13}$ Similarly E Mohamed et al found superficial skin infection in 1 of 15 patients $(6.66 \%) .{ }^{28}$ In our study group only one patient $(3.22 \%)$ had superficial surgical site infection which was adequately treated with intravenous and oral antibiotics. This shows that the rate of infection is much less than reported in earlier studies maybe because of good surgical techniques and better implants used.

\section{CONCLUSION}

Fracture mid shaft clavicle is one of the commonest fracture around the shoulder joint. Undisplaced midshaft fracture can be managed conservatively. Open reduction and plate fixation is a good option for displaced mid shaft clavicle fracture which helps patient for early pain-free movement of shoulder and early return to work. We prefer to use anatomical contoured clavicle plate because it helps in fixation of clavicle to its normal anatomical contour and provides better fixation and stability. Our study favors open reduction and internal fixation with anatomical contoured clavicle plate for displaced midshaft clavicle fracture.

\section{ACKNOWLEDGEMENT}

None.

\section{REFERENCES}

1. Andersen $\mathrm{K}$, Jensen $\mathrm{PO}$ and Lauritzen J. Treatment of clavicular fractures: figure-of-eight bandage versus a simple sling. Acta Orthopaedica Scandinavica 1987;58(1):71-74.

2. Neer CS. Nonunion of the clavicle. Journal of the American Medical Association 1960; 172:1006-1011.

3. Rowe CR. An atlas of anatomy and treatment of midclavicular fractures. Clinical Orthopaedics and Related Research 1968;58:29-42.

4. Rickert AB, Hosalkar H, Pandya $\mathrm{N}$ and Namdari S. Displaced Clavicle Fractures in Adolescents: Facts, Controversies, and Current Trends. J Am Acad Orthop Surg 2013; 21:1-2.

5. Schiffer G, Faymonville C, Skouras E, Andermahr J and Jubel A. Midclavicular fracture: Not just a trivial injury-current treatment options. Dtsch Arztebl Int 2010;107:711-717.

6. Canadian Orthopaedic Trauma Society. Nonoperative treatment compared with plate fixation of displaced midshaft clavicular fractures. A multicenter randomized clinical trial. J Bone Joint Surg Am 2007; 89:1-10.

7. McKee MD, Pedersen EM, Jones C, Stephen DJ, Kreder $\mathrm{HJ}$, Schemitsch EH, et al. Deficits following nonoperative treatment of displaced midshaft clavicular fractures. J Bone and Joint Surg Am 2006; 88(1):35-40.

8. Zenni EJ, Krieg JK and Rosen MJ. Open reduction and internal fixation of clavicular fractures. J Bone and Joint Surg Am 1981; 63(1):147-151.

9. Jupiter JB and Leffert RD. Non-union of the clavicle. Associated complications and surgical management. J Bone Joint Surg Am 1987; 69(5):753-760.

10. Virtanen KJ, Remes V, Pajarinen J, Savolainen V, Björkenheim JM, et al. Sling compared with plate osteosynthesis for treatment of displaced midshaft clavicular fractures. A randomized clinical trial. J Bone Joint Surg Am 2012; 94(17):1546-1553.

11. Xu J, Xu L, Xu W, Gu Y and Xu J. Operative versus non operative treatment in the management of midshaft clavicular fractures: a meta-analysis of randomized controlled trials. Journal of Shoulder and Elbow Surgery 2014; 23(2): 173-181.

12. Böstman $\mathrm{O}$, Manninen $\mathrm{M}$ and Pihlajamaki $\mathrm{H}$. Complications of plate fixation in fresh displaced midclavicular fractures. J Trauma 1997; 43:778-783.

13. Poigenfürst J, Rappold $G$ and Fischer W. Plating of fresh clavicular fractures: results of 122 operations. Injury 1992; 23:237-241.

14. Freeland A. Unstable adult midclavicular fracture. Orthopedics 1990; 13:1279-1281.

15. Zlowodzki M, Zelle BA, Cole PA and McKee MD. Treatment of acute midshaft clavicle fractures: systematic review of 2144 fractures: on behalf of the Evidence-Based Orthopaedic Trauma Working Group. J Orthop Trauma 2005;19:504-507.

16. Allmann FL. Fractures and Ligamentous Injuries of the Clavicle and Its articulation. J Bone Joint Surg [Am] 1967;49:774-784.

17. VanBeek C, Boselli KJ, Cadet ER, Ahmad CS and Levine WN. Precontoured plating of clavicle fractures: decreased hardware-related complications? Clin Orthop Relat Res 2011;469(12):3337-3343.

18. Postacchini F, Gumina S, De Santis P and Albo F. Epidemiology of clavicle fractures. J Shoulder Elbow Surg 2002; 11:452-426.

19. Robinson $\mathrm{CM}$. Fractures of the clavicle in the adult: epidemiology and classification. J Bone Joint Surg Br 1998; 80(3):476-484.

20. Nordqvist $A$ and Petersson $C$. The incidence of fractures of the clavicle. Clin Orthop Relat Res 1994; 300:127-132.

21. Hill JM, McGuire MH and Crosby LA. Closed treatment of displaced middle-third fractures of the clavicle gives poor results. J Bone Joint Surg Br 1997;79:537-539.

22. White RR and Anson PS. Adult Clavicle fractures: relationship between mechanism of injury and healing. Orthop Trans 1989;13:514-515.

23. McKee M. Canadian Orthopaedic Society. Nonoperative treatment compared with plate fixation of displaced midshaft clavicular fractures. A multicenter randomized clinical trial. J Bone Joint Surg Am 2007; 89:1-10.

24. Mittal A, Ramprakash R, Biju R, Prasad SY and Reddy MGK. Effectiveness of low profile pre countered clavicular plate in mid shaft clavicular fractures in young patients. International Archives of Integrated medicine 2015; 2(5):140-146.

25. Ethiraj P, Prathap P, Arun HS and Nagakumar JS. Functional outcome in surgical management of midshaft clavicle fractures fixed with precontoured plate in adults. International Journal of 
Orthopaedics Sciences 2016;2(4):458-462.

26. Wali PC and Nesari SS. Treatment of displaced mid shaft clavicular fracture with open reduction and internal fixation with plate and screws. J Evid Based Med Health 2017; 4(4):201-204.

27. Simonian TL, Simonian LE and Simonian PT. Clavicle Fracture Open Reduction Internal Fixation: Results of Modern Technique. MOJ Orthop Rheumatol 2017; 8(1):298-300.

28. Attia ME and Zanfaly Al. Plate fixation in midshaft fracture clavicle. Egypt Orthop J 2014; 49:299-303.

29. Dhoju D, Shrestha D, Parajuli N, Shrestha R and Sharma V. Operative Fixation of Displaced Middle Third Clavicle (Edinburg Type 2) Fracture with Superior Reconstruction Plate Osteosynthesis. Kathmandu Univ Med J 2011; 36(4):286- 291.

30. Verborgt $\mathrm{O}$ and Pittoors K. Plate fixation of middle-third fractures of the clavicle in the semi-professional athlete. Acta Orthop Belg 2005;71:17-21. Author's Contribution:
PRO- Concept and design, review of literature, statistically analysis and interpretation, manuscript preparation and revision; KS- Data collection, literature
search and review; NR- Data collection, statically analysis and manuscript revision; KW- Manuscript revision and literature review; PT- Literature search and review; UJT- Data collection and literature review.

\section{Work attributed to:}

Department of Orthopedics, Manipal Teaching Hospital, Phulbari, Pokhara, Nepal.

Orcid ID:

Dr. Pratyenta Raj Onta- (i) https://orcid.org/0000-0002-6013-4014

Dr. Krishna Sapkota- it https://orcid.org/0000-0002-2277-8556

Dr. Krishna Wahegaonkar- (D) https://orcid.org/0000-0001-7274-7099

Dr. Niraj Ranjeet- (1) https://orcid.org/0000-0001-5460-5839

Dr. Pabin Thapa- (1) https://orcid.org/0000-0003-1336-5837

Dr. Upendra Jung (1) Thapa- https://orcid.org/0000-0003-1980-5610

Source of Support: Nil, Conflict of Interest: None 